or if the female patient becomes pregnant at any time during pediatric endocrinology care.

This transition plan includes Identifying and maximizing skills needed for successful self-management of diabetes, identifying barriers to successful transitions, creating a plan of interventions to help and encourage the young adult to continue receiving healthcare, collaborating with the adolescent in locating an adult care endocrinologist who will resume the care, providing teens with discharge of care prescription refills, any supplies needed and school/college instruction packets, and attempt four follow up phone calls to the patient during the transition phase after the patient has been discharged from pediatric care.

Results Out of 160 patients (121 type 1 and 39 type 2 diabetes) who started the transition process with at least one visit completed, only 120 patients (75\%) completed the process and were formally discharged from clinic. The remaining patients $(25 \%)$ are still in the transition phase and currently being seen in clinic. We were able to make follow up appointments with adult endocrinologist for the 120 patients transitioned $(100 \%)$ but only 60 patients documented presence for this follow up (50\%).

Conclusion The outcome of transition of diabetes care was faced by some obstacles; these can be grouped into:

1-Psychological factors: Adolescents burnt out, depression and adjustment disorders. Lack of Independence and readiness.

2-Factors affecting access to health care: Change of health care insurance, lack of insurance, lack of financial means to pay for visit; and transportation problems.

3- Communication factors: Inability to maintain contact after transition (patients not responding to communication from providers, disconnected phone number).

Bridging the gaps in health insurance during this transitional period remains of great importance. Understanding the differences in learning styles between individuals in this transition period will also reflect the readiness for transition.Training health care professionals for this delivery of care is also crucial.

\section{P356 ITALIAN PEDIATRICIANS NEED KNOWLEDGE ABOUT MALTREATMENT AND ABUSE OF CHILDREN. ACTIONS MORE THAN WORDS}

Luigi Nigri*, Paola Mlglioranzi. FIMP (Italian Pediatrician Doctor Federation), Rome, Italy

\subsection{6/archdischild-2019-epa.703}

Italian Medical Doctors do not receive adequate information about the reality of child abuse and maltreatment during their university studies and career, neither during their Specialization in Pediatrics. This lack of knowledge makes it difficult to recognize and to know how to intervene when we are in our own surgeries (if we become general doctors or pediatricians). In 2017 Istat (Italian Institute of Statistics) registered a hundred thousand children mistreated, of which 15 per cent were victims of domestic violence (one out of 5 of the total number of Italian children). The FIMP (Italian Federation of General Pediatricians), the organization which encompasses more than 7 thousand general pediatricians of the country $(80$ per cent), conscious of this difficulty has decided to improve the knowledge of general pediatricians, by organizing one day training session about all the principal types of abuse situations, the symptoms, signs, diagnosis, intervention in case of child abuse and maltreatments. There have been 26 sessions over the last 2 years, all around the country, each with about 50 partecipants and were conducted together with the Italian Society of Pediatricians (SIP). After this first step last June a national study group was instituted, with a national coordinator and one or two representatives for each of the twenty Italian region. This group aims to help spread knowledge about these themes and to create network of cooperation among professionals who take care of children in these situations. Last November the FIMP signed an agreement with the Italian Authority's Guarantor for Children and Adolescents to work together for create a map of every structure dedicated to the care of children and adolescents, such as hospitals, surgeries, health districts, law courts, courts for minors of every town and region, to make it easier for the doctors to intervene, cooperating with professionals in his own reality. The group also has an important role of psychological support of collegues when they feel in doubt or are afraid of intervening. As the International Convention of New York says: to pursue the best interest of the child, even if it is not so simple.

\section{P357 COST-EFFECTIVENESS ANALYSIS FOR TREATMENT OF VISCERAL LEISHMANIASIS IN ARMENIA}

1,2,3 Hripsime Apresyan*, 4,5,6Erik Grigoryan, ${ }^{1}$ Mark Grigoryan, ${ }^{7}$ Edgar Tsarukyan, ${ }^{1,2}$ Vigen Asoyan. 'Y Yerevan State Medical University after Mkhitar Heratsi, Yerevan, Armenia; ${ }^{2}$ Muratsan University Hospital Complex, Yerevan, Armenia; ${ }^{3}$ Wigmore Clinic, Yerevan, Armenia; ${ }^{4}$ Armenian State University of Economics, Yerevan, Armenia; ${ }^{5}$ Swiss UMEF University, Yerevan, Armenia; ${ }^{6}$ Amberd Research Center, Yerevan, Armenia; "Nork" Infectious Clinical Hospital, Yerevan, Armenia

\subsection{6/archdischild-2019-epa.704}

Background The leishmaniases are neglected and poorly reported diseases with underestimated or undetermined incidence in most countries of the WHO European Region. Since the late 1940s, the traditional drugs for VL treatment have been pentavalent antimonials $\left(\mathrm{Sb}^{5+}\right)$.

In the 1980s, conventional amphotericin B deoxycholate (ABD) was introduced, followed by lipid formulations of amphotericin B showing high efficacy and low toxicity. Liposomal amphotericin B (LAB) is a first-line therapy in the WHO European Region, but the price is still very high in Europe as most European countries do not benefit from the preferential price given to WHO for low- and middle-income endemic countries. Duration of treatment with Meglumine antimoniate is minimum 30 days and with $\mathrm{LAB}-\max 7$ days.

Cost-effectiveness ratios derived through cost-effectiveness analysis can be used to compare the efficiency of different health-care programs, although such comparisons should be made cautiously because of the uncertainties associated with many estimates of cost and effectiveness. Armenia is a middleincome country, an endemic region for Visceral Leishmaniasis. Objective The purpose of this study was to evaluate which of $\mathrm{LAB}$ and Meglumine antimoniate treatments is more costeffective in Armenia.

Methods A retrospective economic analysis has been performed to determine the cost-effectiveness of LAB in patients with VL using 24-month data from 'Nork" ICH. The analysis has been conducted from a third-party payer's perspective.

On the basis of historical data average age of patients has been calculated - 24months, with mean weight $11.5 \mathrm{~kg}$. Average daily cost of treatment with LAB has been calculated as 
follows: $a^{*}$-average cost of tests b-average cost of treatment $c^{*}$-average cost of LAB d-other fixed costs e-average opportunity cost of labor(patient's real wage).

*-during calculation Armenian market prices have been used

Eventually, average cost of LAB treatment has been determined.

Results Since average cost of treatment with Meglumine antimoniate is known - 36.7EUR per patient per day, it can be compared with LAB treatment cost - 122.2EUR per patient per day. Calculating the total costs of whole procedures enables to elaborate on big differences in the costs of two treatment options (Meglumine antimoniate 1100EUR vs LAB 855.4EUR).

\section{Abstract P357 Figure 1}

Conclusions Treatment with LAB is cheaper in comparison with Meglumine antimoniate.

Owing to lesser hospitalization days the former decreases the risk to get nosocomial infections which in its turn prevents possible cost increase.

\section{P358 HOW CAN WE PROMOTE BETTER CARE FOR CHILDREN WITH CANCER ? DISCUSSION OF A CHILD- AND FAMILY-CENTRED CARE APPROACH FOR EACH STAGE OF THE CHILD AND FAMILIES TREATMENT JOURNEY}

Imelda Coyne*. Trinity College Dublin, Dublin, Ireland

\subsection{6/archdischild-2019-epa.705}

Family-centred care is viewed as a way of caring for children and their families within health services which ensures that care is planned around the whole family, not just the individual child/person. It is a popular and widely used model in children's healthcare around the world. However research indicates that the practice of family-centred care is inconsistent and problematic with no solid evidence that FCC works or makes a difference to health outcomes. This lack of evidence coupled with continual reporting of problems with FCC has led to calls for a re-examination of the suitability of the model and suggestion that child-centred care may be a more appropriate model for children's nursing. Family-centred care is seen as offering ways to facilitate parents' involvement and active participation in their child's care. However, current descriptions of the model does not offer clear guidance on how to involve and support children's participation in their own care. Therefore a new child- and family-centred care framework is required for parents and children with cancer.

In this paper I will outline the core principles of familycentred care and consider the mixed evidence about the benefits of this model for children, parents, nurses and the health system. Parents and families have an essential role in caring for their children throughout the cancer treatment journey. But FCC needs to incorporate the rights of the child to participate in all aspects of health care delivery in conjunction with the need of their family. We need to ensure a child-centred perspective, which entails seeing each child as an active agent, the child's needs are the starting point for care planning and provision, and where each child's preferences, values, family situation, social circumstances are considered. Taking a child-centred approach requires all health professionals to include the child's perspective in their actions and care delivery. It is important that the practice of child and familycentred care is flexible as needs will alter with each stage of inpatient cancer care and transition to home setting. The paper will conclude with guidance on how professionals can use a more child and family-centred care approach in their daily practice with children and families.

\section{P360 PROLONGED ADMISSIONS IN PAEDIATRICS - THE REALITY OF A PORTUGUESE CENTRAL HOSPITAL}

Marta Pinheiro*, Vanessa Gorito, Tiago Magalhães, Margarida Ferreira, Ana Maia, Manuel Fontoura.

\subsection{6/archdischild-2019-epa.706}

Department of Paediatrics. Centro Materno Pediátrico, Centro Hospitalar e Universitário de São João, Oporto, Portugal

Introduction A Diagnosis Related Groups is a patient classification system that standardizes prospective payment to hospitals considering the main and secondary diagnoses, surgical procedures, complications, patient's age and sex and discharge status. There are hospitalizations of normal duration, short admissions, long-term admissions and prolonged admissions according to the episode whose hospitalization time is the expected, lower, upper or greater than the maximum threshold of the respective defined hospitalization time, respectively. The objective of this study was to determine the incidence and the reasons for prolonged admissions.

Methods Retrospective review of medical records of patients admitted on Department of Paediatrics and analysis of the cases classified as prolonged admissions, during the year 2017.

Results There were 1493 hospitalized children with encounter for antineoplastic chemotherapy, fever and hypoxemia as the three most coded diagnoses; 1240 (83\%) admissions had a normal length of stay, 177 (11.9\%) were short admissions, 48 (3.2\%) long-term admissions and 28 (1.9\%) had prolonged evolution. In this latter group, $57 \%$ were female, the mean age was 3 years old, and the length of stay was 27 days (7-127 days), on average. Fifteen patients came from the neonatal intensive care unit, five from the outpatient clinic, two from the emergency department, and the others from other paediatric units; $53.5 \%$ of patients had a chronic pathology, and $25 \%$ had already been hospitalized in the same hospital. During the admissions in the study, 7 (25\%) patients had devices, $18(64.3 \%)$ had some complications (77.8\% had an infection), 6 (21.4\%) underwent invasive techniques and $3(10.7 \%)$ were hospitalized to resolve the social situation. Liveborn infant delivered vaginally and by caesarean and symptomatic epilepsy/epileptic syndromes with complex partial seizures were the most prevalent diagnoses in this group and each episode had four additional diagnoses, on average.

Discussion Most patients of this study with prolonged hospitalizations are complex, which is expected in a central hospital, requires a differentiated team and seems to justify the longer duration of hospitalization. Other studies reported that hospitalizations of children with medical complexity have lengths of stays that are typically longer than those for children without medical complexity. In this study, no comparative studies were possible due to the lack of similar patients with normal length hospitalizations, prospective studies were necessary. 